\title{
General Discussion to the Papers of Dr Carlos, Miss Trieschmann, and Dr Huber
}

Professor V. Paeslack (Chairman). A good chance now to go into the discussion of the three last papers which are given free now. Sir Ludwig?

SiR Ludwig GutTMANN. I was very interested in that paper of Roberta Trieschmann. You told us you had I per cent suicides in your material, that is a very high percentage. Could you please tell us first how many were married, unmarried and how many were male or female and what was the cause of their suicides, whether socially, sexually. The other question I'd like to ask is this. What you told us was a very sensible talk on the psychology of paraplegics. This, of course, is a matter primarily for a doctor in charge of a spinal unit. I would like to ask you what is your relationship to the medical staff? Are you working independently or are you working under the leadership of the Director of your spinal unit?

Miss TrieschmanN (U.S.A.). Dr Guttmann, the studies that I refer to unfortunately do not give much data other than the statistic on suicide and I think this is unfortunate. I would like to see follow-up studies documented to give us information on exactly the questions you asked. For example, all we know from the 423 patients followed at Ranchos Los Amigos Hospital is that 34 per cent of them seem to be related to personality types of problems, the same thing as Price's study in the University of Minnesota just mentioned that out of all the deaths traumatic cases $8 \cdot \mathrm{I}$ per cent nobody really spells out what are the details. I would suggest that we have studies to find out why these people are taking such drastic steps to end their disability. Secondly Sir, I have worked too in my position as Clinical Psychologist at the Rehabilitation Centre in the University of Washington, in Seattle with John Young at Phoenix, at the Good Samaritan Hospital and at the University of Cincinatti Hospital. I have become part of the rehabilitation team working side by side with the physicians, nurses, physical and occupational therapists as one of the members of the team consulting on all patients. I think it is most important to have the psychologist as an active participating member of the team, not independent of it. Secondly, because I don't believe that people with spinal cord injury necessarily have psychological problems I would think that there would be the role for the psychologist to at least be aware of each individual case and available to consult with the team on any little difficulties of cooperation or what else the label is. It has been my experience that these problems of lack of motivation sometimes are terribly responsive to slight variations in the environment such as Dr Cheshire described this morning with respiratory conditioning, like giving very concrete feedbacks. It's amazing the sort of increases in behaviours that you can find. Does that answer your question Sir?

SIR LUDWIG. Yes, thank you.

DR MEINECKe (Germany). First of all I would like to do a small correction to Dr Huber's paper. He quoted me when he told you that I stated that a man unwilling to work before his injury will not become very ambitious to work after the injury, probably he overlooked that I in that paper quoted Sir Ludwig's views that a work-shy individual may not necessarily become a hard worker following paraplegia. Secondly, with regard to Miss Trieschmann's paper, to pre-morbid personality, I have the feeling that in that field a psychologist could be of great value to us to clarify the situation, what the patient's pre-morbid personality was, because that may open some doors or they show us some limits we can't change though the psychotherapist probably can do so.

Miss TRIESChMANN. If we look at the pre-morbid personality styles maybe 20 per cent of the individuals with spinal cord injury may have a pre-morbid history and that will be working against them in functioning with spinal cord injury, as he never worked all that well, had multiple difficulties with the law, alcohol, drug abuse etc. I think that for those individuals it is very difficult to produce some rather dramatic changes and maybe this accounts for 20 per cent of the population maybe at most. But then we have the other 80 per cent of our patients and maybe 20 per cent of those are what 
I call super winners, they are very adept individuals in coping with their environment no matter what happens. They do very well almost despite us and those are the ones that make us feel very good because they were very successful. And then we've got the middle 60 per cent, maybe this is the average man or woman who are going along and doing O.K. not super winners but not losers either and the spinal cord injury can be enough to complicate their lives so that if we had psychological and social intervention in this 60 per cent we might be able to increase our winners to 80 . I would like to see this study done, I would like to take the opportunity to participate with others in rehabilitation in spinal injury to see if we could pull off this 80 per cent. And I think that if you have psychological involvement just for that small percentage, maybe 5 per cent that have maybe psychiatric diagnoses, that would warrant a psychiatric diagnosis, were perhaps not utilising all the resources that were available.

Unknown voice. But how would you identify them?

Miss TrieschmanN. Well I think the ones that have very disruptive behaviour are the ones that are identified right away, and all that I can say is that I think that almost every individual that has a spinal cord injury could benefit from just a consultation or availability of consultation with a psychologist, social worker etc. not because they're crazy, but just because it is a rather difficult change for an individual with spinal cord injury.

DR GRIfFITHS (Australia). I'm sorry to come back to Miss Trieschmann again here, it's regarding suicides. I was in a spinal centre in Asia last October and this was an excellent centre, the patients were looked after very well and the nursing management was beautiful but the patients had nothing to do, and they were looked after very well physically but they averaged nine suicides a year. I think this is what we have to think about, not just giving them-restoring life but prolonging life, that the quality of life that we are prolonging or the new life that we are giving them, if we give them nothing to do then they will not want it to prolong. You must make life useful, restore some purpose in it, make them feel part of society, a man needs to leave home, he needs to go out and earn a little, make himself like his other family and form a social intercourse in his work atmosphere, all the similar needs to run a home and feel part of society and a useful person again. Unless we do this I don't think we are fulfilling our role in treating the whole patient, the whole personality. I would agree with Miss Trieschmann in her suicide figures as certainly my experience last year was this. Secondly, one point Dr Huber made about, I think it was personality not changing. The leopard doesn't change its spots. We have among our people our young aggressive males, many of whom were accident prone prior to their admission with a spinal fracture. Many of them had accidents before and these people have problems, so many before they have this final spinal injury, these are I think quite a large proportion of difficult people with rehabilitation to make his life worth it. 